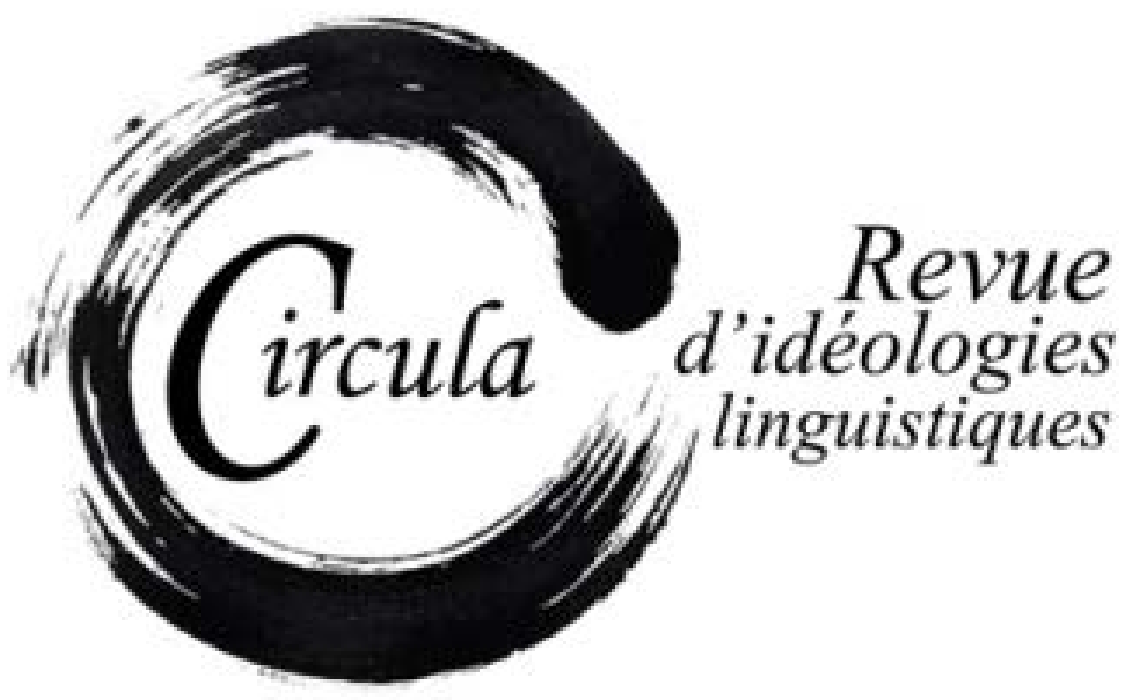

TITRE: LOS MANUALES DE ESTILO PERIODÍSTICOS PARA LAS VERSIONES ON LINE: LAS REPRESENTACIONES DEL LECTOR Y SU INCIDENCIA EN LA REGULACIÓN DE DISCURSOS Y PRÁCTICAS

Auteur(s): Elvira Narvaja de Arnoux, Universidad de Buenos Aires

Revue: Circula, NumÉro 2, PAGES 138-160

ISSN: 2369-6761

DiRECTEURS: Wim REMYSEN ET SABINE SCHWARZE

URI: HTTP://HDL.HANDLE.NET/11143/7981

DOI: $10.17118 / 11143 / 7981$ 


\title{
Los manuales de estilo periodísticos para las versiones on line: las representaciones del lector y su incidencia en la regulación de discursos y prácticas
}

Elvira Narvaja de Arnoux, Universidad de Buenos Aires elviraarnoux@gmail.com

\begin{abstract}
Resumen: La implementación de versiones on line de los periódicos obliga a los manuales de estilo producidos en el ámbito hispánico a considerar las formas de escritura en Internet. Al hacerlo retoman de los textos que las analizan las representaciones de un lector global, poco entrenado, de atención dispersa y sensible a la multimedialidad. A partir de ello, los manuales establecen reglas para la discursividad periodística en Internet, particularmente brevedad, simplicidad, claridad y restricción de los juegos de sentido. Por otra parte, como la interactividad es no solo una posibilidad del medio sino un requerimiento de las empresas periodísticas para reducir costos, establecen reglas de netiqueta que regulen las intervenciones. El artículo analiza estos aspectos y se interroga respecto de si esos modos de leer y de escribir que los manuales hacen circular incidirán, cuando dominen, en el desarrollo de las actividades intelectuales de aquellos que privilegien en su consumo esta prosa informativa.
\end{abstract}

Palabras clave: prensa on line; manuales de estilo periodístico; glotopolítica; lector global

\begin{abstract}
Implementing on line editions of newspapers compels style guides used in the Spanish-speaking world to take into account the different ways of writing on the Internet. Thereby, they take from the texts dedicated to the analysis of such ways of writing some ways of representing a global reader, less trained, scattered and sensitive to multimediality. Based on these features, style guides establish rules for on-line journalistic discourse, focusing on brevity, simplicity, clarity and the restriction of sense games. On the other side, since interactivity is not only a possibility offered by the medium but also a requirement of journalistic companies in order to reduce costs, they establish netiquette rules aiming to regulate the readers' interventions. The following paper attempts to analyze these issues, wondering if those ways of reading and writing, spread by the style guides, might be influent, once they become dominant, upon the development of the intellectual activities of those preferring this kind of prose.
\end{abstract}

Keywords: on line daily press; manuals of style for journalists; glotopolitics; global reader 


\section{Introducción}

Los manuales de estilo periodístico ligados a los órganos de la prensa escrita aparecen en el ámbito hispánico en la década de los setenta y ochenta del siglo pasado y su presencia se acentúa en los noventa. En la primera década de este siglo, una nueva generación de manuales debe elaborar dispositivos normativos propios no ya en relación con el soporte papel, al que estaban acostumbrados desde los orígenes de la prensa, sino con el soporte electrónico, en el que ya habían incursionando al poner en Internet las versiones que aparecían en el soporte papel. Así como los primeros manuales abrevan en los instrumentos lingüísticos tradicionales (gramáticas y diccionarios) los últimos parten de los textos sobre medios digitales y los adaptan a la práctica periodística atendiendo a aspectos lingüísticos y discursivos generales. Para marcar lo reciente de los cambios, Fogel y Patiño (2007: 7) señalaban: "la nueva prensa es tan joven que no tiene ni teoría, ni historia, ni manual actualizado de sus innovaciones"1. De allí que se encuentren pocos exponentes de manuales para versiones online.

Debemos destacar, y ese es el objeto de nuestra exposición, que estos manuales construyen la representación de un lector global, origen de un ideal de lengua y de prosa informativa que orienta el dispositivo normativo. Enmarcaremos primeramente los manuales de estilo señalando los dos tipos que corresponden a los dos soportes, papel y digital. Luego nos centraremos en los producidos para las versiones on line o, en términos amplios, los ciberperiódicos o periódicos electrónicos atendiendo a la representación del lector y a los rasgos que destacan de la prosa informativa, en títulos, copetes y cuerpo del texto. Y, finalmente, nos referiremos al desplazamiento de la transparencia lingüística a la limpieza moral que se opera con la llamada netiqueta, es decir con la cortesía en la red.

Si bien privilegiaremos los manuales de estilo para este tipo de periódicos, aludiremos en algunos momentos a los anteriores, que además siguen vigentes, ya que ambos se asignan una función rectora que excede el campo del lenguaje (aunque se propongan determinar la corrección lingüística y regular la discursividad). Asimismo, cuando nos parezca relevante mostraremos las semejanzas con las artes de escribir de la llustración, que fueron elaboradas en otro momento de la expansión de la cultura escrita pero relacionadas también con el desarrollo de los medios gráficos y de textos didácticos y de divulgación para mostrar la morosidad de algunas representaciones o la posibilidad que tienen de ser activadas en otras circunstancias. Los manuales de estilo periodístico se interrogan, por ejemplo, como los textos normativos de fines del siglo XVIII y principios del XIX, sobre el nuevo lector y las características que debe tener la prosa informativa para facilitar la lectura. En uno y otro caso se deciden por "perturbar" lo menos posible al lector y para ello proponen evitar digresiones y oraciones complejas, preferir el orden directo en la oración y elegir un léxico corriente.

Inscribimos nuestro trabajo dentro de la Glotopolítica, que estudia las intervenciones en el espacio público del lenguaje y las ideologías lingüísticas que activan y sobre las que inciden. Estas se vinculan con posiciones sociales y la indagación tiende a analizar los modos en que participan en el

1. En este caso como en los otros que aparezcan la traducción me pertenece. 
cuestionamiento, instauración, reproducción o transformación de entidades políticas, relaciones sociales y estructuras de poder tanto en el ámbito local o nacional como regional o planetario (Arnoux, 2000, 2011). En ese sentido, los manuales de estilo periodístico, en tanto instrumentos lingüísticos (Auroux, 1994), son intervenciones realizadas desde un lugar social de autoridad. Este deriva del peso actual de los medios y está reforzado, en algunos casos, por la participación de representantes del mundo académico. Al establecer un dispositivo normativo que regula la lectura y la escritura de la prosa informativa muestran que más allá de contribuir a la formación de la opinión pública por sus contenidos, modelan las subjetividades "hablantes" indicando formas y prácticas discursivas legítimas.

Cuando analizamos las representaciones sociolingüísticas en instrumentos como los manuales de estilo no podemos dejar de atender a las distintas temporalidades en que estas se inscriben (Arnoux y del Valle, 2010). Algunas están ligadas a la coyuntura y a las transformaciones tecnológicas que se han operado, por ejemplo las que derivan de la aparición de las redes sociales; otras responden a fenómenos que convocan una temporalidad media como la conformación de áreas idiomáticas o, incluso, la memoria del propio género; y otras anclan en temporalidades más amplias como la de los instrumentos lingüísticos que han regulado la discursividad en Occidente: en nuestro caso, retóricas y artes de escribir. En ese sentido, pensemos que al haber elegido como nombre del género ese casi oxímoron "manual de estilo" (Arnoux, Blanco y di Stefano, 1999) instalan una vieja polémica, que se acentúa con el Romanticismo, respecto de si son necesarias las normas en la producción escrita o si el talento individual es suficiente, pero, a la vez, aceptan, por su misma existencia genérica, el fuerte legado de la tradición retórica: el estilo como parte de la elocutio requiere para su enseñanza un dispositivo normativo.

Asimismo, hay que considerar que las ideologías lingüísticas articulan representaciones acerca de diferentes objetos, en nuestro caso, del posible lector, los modos de leer, el ideal de prosa informativa, la relación de la escritura con otras prácticas. Pero hay un centro que da sentido al juego de representaciones y que deriva de situaciones sociales: en los nuevos manuales de estilo periodísticos el foco es, como anticipamos, el lector. Pensemos que los medios necesitan economizar en la producción, para lo cual, por un lado, la participación de los lectores enviando noticias, fotos o videos es decisiva, y, por el otro, deben buscar formas de financiamiento no tradicionales para lo cual la ampliación de la audiencia es un paso fundamental. Internet, por su parte, facilita el conocimiento del posible destinatario, en algunos casos, incluso, sectorizado por los intereses que comparten. En ese sentido, Escribir por Internet de la Fundación del Español Urgente (Fundéu, 2012: 82) señala: "nunca como ahora las empresas informativas habían tenido un conocimiento tan preciso de su audiencia, los editores pueden generar contenidos de acuerdo con las características de cada soporte para presentar el mejor producto posible". Muchas de las ilustraciones que presentaré provienen de esta publicación, en los otros casos lo señalo explícitamente. Debo aclarar también que Escribir en 
Internet es una obra que reúne artículos institucionales y notas firmadas por diferentes autores pero yo privilegiaré su carácter colectivo y no indicaré al responsable de cada aporte².

\section{Manuales de estilo periodísticos}

La elaboración, por parte de los medios gráficos, de textos que dejan de ser simples folletos de uso interno de las redacciones para convertirse en libros que se difunden comercialmente tiene que ver, en primer lugar, con la función social que los medios se asignan. En un trabajo anterior (1999), elaborado a partir de la aparición en 1997 de los de La Nación y Clarín, en la Argentina, habíamos señalado que

Su publicación constituye una operación ideológica de los medios gráficos destinada a construir una representación de sí mismos como instituciones responsables de un magisterio moral y lingüístico en el momento en que, de hecho, el conjunto de los medios periodísticos asume funciones sociales ejercidas antes por otras instituciones - escuela, iglesia, justicia, fundamentalmente - y en que los grandes diarios tienden a controlar otros medios gráficos y a ubicarse como cabezas de grupos mediáticos. (Arnoux, Blanco y di Stefano, 1999: 177)

La importancia de los manuales de estilo producidos por diarios del ámbito hispánico llevó a Gómez Font a afirmar que "las verdaderas guías del uso del español actual son los manuales de estilo y la mayor parte pertenecen a los medios de comunicación"; estos son "los verdaderos maestros del español ya que se encargan de difundir los nuevos usos de la lengua” (Font, 1998: 1).

Pero, por otra parte, hay que considerar que el proceso de globalización ha incidido, primero, en la preocupación - común por parte de medios de diferentes países del mundo hispánico y de las agencias de prensa cuyos servicios informativos tienen ese alcance - por elaborar normas frente a lo que se visualizaba como un vacío normativo de las instituciones que debían regular el área lingüística en un momento en el que se temía la invasión de términos extranjeros y construcciones que afectaran la lengua. Luego, en los años noventa, es lo que impulsó el apoyo que brindaron los medios a la Real Academia Española y al Instituto Cervantes para que elaboraran instrumentos lingüísticos que abarcaran el área idiomática y permitieran adoptar criterios comunes. La implementación de medidas relacionadas con la política lingüística de área idiomática, que recibió en 2004 el nombre de panhispanismo, llevó a que las orientaciones destinadas a los medios gráficos se articularan con la labor de estas instituciones y privilegiaran aspectos normativos del castellano respecto de la morfología o las construcciones y respecto del léxico, particularmente de los neologismos. A partir del Congreso de la Lengua de Zacatecas (1996) se evidenció la decisión de establecer normas comunes a toda el área, que facilitaran la tarea de los medios, de lo que da cuenta la actividad de la Fundación del Español Urgente (2005) y la publicación del Diccionario Panhispánico de dudas (2005), cuyos criterios

2. Si bien Mario Tascón, el responsable, convocó a 41 expertos, me referiré al libro como texto unitario proveniente de una fuente institucional. En las citas de este texto, pondré solo la fecha (2012) y el número de página. 
y normas las redacciones se comprometían a incorporar. Respecto de esto, el Manual de español urgente, heredero del Manual de estilo de la Agencia EFE reitera en su última edición "la necesidad de normalizar el lenguaje", de lograr "la homogeneidad de criterios idiomáticos" y contribuir a "la unidad de la lengua", que constituye "un bien que importa defender en el seno de la comunidad hispanohablante” (Fundéu, 2008: 16). Finalmente, con la irrupción de las versiones on line (accesibles por computadora ${ }^{3}$ ) que amplían notablemente el número de lectores y que los lleva a avizorar un espacio planetario, los medios ocupan otra vez la escena normativa, si bien no se interesan ahora por los aspectos tradicionales ${ }^{4}$ sino por el desarrollo del lenguaje en Internet ${ }^{5}$ : "Es en Internet donde se juega el futuro de la lengua" (Fundéu, 2012: 21); La Voz del Interior (2006: 161), por su parte, va a afirmar: "[Internet] es un reto en la historia de las empresas periodísticas, en particular de los diarios, que buscan atraer lectores jóvenes y nuevas oportunidades de negocios". Los manuales tratan, por un lado, de orientar no solo a los periodistas sino a todos aquellos que participan en los nuevos modos de informar y que interactúan con la prensa. Y atienden, por el otro, a la articulación entre lo verbal y las formas de comunicación multimedial, que Internet posibilita y que los medios transitan por constituir muchos de ellos grupos mediáticos que integran prensa gráfica, radio y televisión. Sin embargo, no pueden dejar de sostener los principios generales de homogeneidad y corrección lingüísticas. Así la Fundéu señala que tiende a "formar en la mente de los lectores de la obra una preocupación constante por los usos idiomáticos en sus aspectos generales [...] o aspectos muy particulares de la variación lingüística destinados a eliminar los localismos"6 (Fundéu, 2012: 16). Tiende también a "proporcionar criterios de coherencia en el uso del idioma para evitar su empobrecimiento y hacer frente a la invasión indiscriminada de extranjerismos o neologismos innecesarios" (Fundéu, 2012: 29).

En los nuevos manuales no solo reaparecen temas y representaciones de las artes de escribir ilustradas sino que también se evidencia la voluntad de legitimarse inscribiéndose en la amplia tradición retórica. El Prólogo de Escribir en Internet, por ejemplo, señala:

3. No hay demasiados avances en las normativas periodísticas para soportes complementarios como el teléfono celular. 4. Si bien estos aspectos normativos son comunes al soporte papel y al on line, en este se perciben tensiones entre las normas académicas y los requerimientos de rapidez y eficiencia de los nuevos medios. Nogueira (en prensa) demostró detenidamente la complejidad de estas relaciones.

5. En la red, los medios habían insertado primero los textos elaborados para el soporte papel (periodismo 1.0) y luego tuvieron que considerar ediciones on line, que se iban distanciando de la versión en papel e incluyendo opciones (periodismo 2.0) que permitían comentarios o que hacían intervenir las redes sociales (por ejemplo, aportes en Twitter o Facebook). Además de este aspecto interactivo debían contemplar la hipertextualidad y la multimedialidad.

6. El resalte me pertenece. 
Este libro plantea en sus bases teóricas los viejos problemas de la antigua retórica clásica en su aplicación a un mundo tecnológico radicalmente original. La constante relación entre el autor y los destinatarios sigue siendo el eje central de los problemas [...]. Antiguas virtudes estilísticas, como la brevedad y la claridad, quedan privilegiadas en esta nueva situación supeditada a factores muy distintos de carácter tecnológico como el número de espacios disponibles o la legibilidad del texto. (Fundéu, 2012: 15)

En su afán por asociar su empresa al espíritu clásico multiplica las referencias a estos antecedentes:

La página y la pantalla recuperan parte de los problemas que habían aparecido en la época clásica entre la página del texto y el lienzo del pintor, y añaden la relación maravillosa de la hipertextualidad, posibilidad que hubiera hecho las delicias de los comentaristas de textos del Humanismo. (Fundéu, 2012: 16)

En las artes de escribir la analogía entre texto escrito y pintura se establecía fundamentalmente para reforzar el principio de armonía y desprenderlo del mundo de los sonidos y por lo tanto de la oralidad (Arnoux, 2008: 333-334). En este caso el juego metafórico se literaliza y los que se comparan son página y pantalla. Este desplazamiento es significativo en la medida en que se convoca la vista valorizándola como captadora del dibujo del texto, similar a un cuadro, y vía primera de una lectura orientada por el dispositivo gráfico. De allí que dominen las metáforas icónicas: tanto la más insistente y anterior de que hay que escribir con el modo de la pirámide invertida como la que indica que se lee en forma de F.

\section{Manuales de estilo para ediciones periodísticas on line: la repre- sentación del lector}

En esta época, entonces, la difusión de la escritura en Internet ha llevado al desarrollo de nuevos textos normativos que son los manuales de estilo periodísticos que, si bien tienen una historia anterior, se ven obligados a pensar los modos en línea de la escritura y las reglas para adecuarse a ella. Van a aparecer, así, nuevos ideales de prosa informativa distintos de los propios del soporte papel y se van a centrar en un tipo de lector que descubren al mismo tiempo que construyen.

La posibilidad de abrir el medio a los lectores, que permite reducir los costos de producción de las empresas periodísticas, es presentada, gracias a un desplazamiento ideológico particular, como expresión de la calidad democrática:

La autoría de los contenidos se ha democratizado, la publicación no es exclusiva de los especialistas de la información contratados por los medios, sino que el ciudadano se vuelve autor. Cualquiera puede generar información, comentarla y compartirla, la autoría se traslada a la sociedad en lo que viene a llamarse periodismo ciudadano. (Fundéu, 2012: 26) 
Este cambio es pensado también como un nuevo modelo de comunicación: "Estamos migrando de un modelo de disertación a otro de conversación, en el que 'usuario' es el nuevo nombre del lector. Ello demuestra que el diario sirve para muchos fines, entre ellos, la creación colectiva de contenidos" (La Voz, 2006: 163). Los constantes desplazamientos de lector a usuario evidencian, a su vez, un imaginario de consumo de la información con las leyes que otros consumos imponen: ajustar todo al potencial cliente.

Las decisiones respecto de la textualidad derivan de la caracterización de ese potencial destinatario. Por un lado, es aquel que necesita contextualización permanente: en forma implícita por la jerarquización de la noticia - "priorizar los contenidos de mayor importancia, situándolos al inicio de la zona de lectura" (Fundéu, 2012: 61) - o, explícitamente, por el señalamiento de la hora de actualización. Es un lector que debe ser ubicado: "dónde está, qué tiene que hacer, qué es lo más importante de la página..." (Fundéu, 2012: 65), "en internet gusta que nos digan lo que tenemos que hacer" (Fundéu, 2012: 67). Las opciones para una lectura multilineal están dadas por cierto por el texto, que señala los enlaces posibles. Además es un lector insensible a las explicaciones especializadas, que se detienen en la dinámica y los modos de decir de determinados campos sociales, ya que se interesa fundamentalmente por lo que lo atañe. Associated $\operatorname{Press}^{\top}$ (2012) plantea que "a la gran mayoría de los lectores no les interesan los detalles legales, los procedimientos formales, los formulismos, los tecnicismos sino qué es lo que ocurrey, sobre todo, en qué medida les afecta". De allí que señale que el estilo ideal está "despojado de jergas. No utiliza ninguno de los lenguajes característicos oficiales, de políticos, funcionarios, burócratas, militares, jueces, policía, técnicos, médicos, especialistas, publicistas, sino que los traduce a un lenguaje comprensible".

Los rasgos que se le asignan al lector se desplazan, por otro lado, del sujeto que lee, al individuo social vinculado con una franja etaria y con modos de relacionarse con el mundo y los otros. Esto se debe a que se desprende la figura del lector del efecto de la construcción textual y se la proyecta sobre un lector externo al que se le atribuyen características estables. Juventud, apertura mediática, tendencia al descubrimiento personal y búsqueda de la innovación son los rasgos que lo identifican, a la vez que se inclina tanto a la información como al entretenimiento, actividades fácilmente intercambiables ya que sus límites no resultan demasiado claros. Algunas de las representaciones pueden asociarse con la imagen de un niño: "salta de un texto a otro, sin ningún miramiento, según sus intereses" (Fundéu, 2012: 64). Si bien los manuales parten de la representación de una franja etaria pueden incluir a aquellos que se sientan jóvenes, es decir, que se puedan incluir en la categoría de lector propuesta. Los rasgos que se señalan ${ }^{8}$ tienden a diseñar la figura de aquel destinatario sensible al nuevo producto, por eso la cercanía en algunas apreciaciones con el discurso publicitario:

7. Todas las citas de esta agencia que incluyo corresponden a la entrada "El estilo periodístico" que es dentro del Manual de estilo (on line), al que se accede por suscripción, una síntesis de dos páginas.

8. Los fragmentos que cito, separados del cuerpo del artículo, corresponden a una ponencia del editor general del diario El Universo de Guayaquil, 2003, retomada por el Manual de La voz del interior (2006: 171-172). 
Es joven o tiene una actitud joven ${ }^{9}$. Es una generación menos lectora o refractaria a la solución monomediática de lo impreso y es más abierta a códigos visuales, diseño, interactividad, efectos tecnológicos, etcétera.

Le gusta descubrir cosas: no es pasivo y explora Internet hasta encontrar las páginas que más le atraigan a sus inquietudes de información y de entretenimiento. Demanda innovación permanente.

Se parte de la idea de que el lector on line no es el habitual de los textos verbales complejos sino que es alguien que tiene cierta experticia en los códigos visuales y en la interactividad propia de los nuevos medios. Así, si bien navega para descubrir, el texto debe facilitarle la lectura y entusiasmarlo para que no deje de leer porque solo "elige lo que más le gusta". Se aconseja, así, "un lenguaje sencillo", "un estilo lo más directo posible" que no retrase la información importante, el "aligeramiento del volumen de un artículo", es decir, con oraciones y palabras cortas: no utilizar, por ejemplo, "subalternizar por subordinar" (en esta apreciación del medio las diferencias de sentido se neutralizan gracias al criterio de brevedad). Se propone también el uso de un verbo fuerte al principio de un párrafo para llamar la atención de los lectores. Fundamentalmente, se considera que se debe evitar que "se agote la paciencia del lector o se lo aburra" (Fundéu, 2012: 51-52 ${ }^{10}$ ), por lo cual no hay que "obligar a los lectores a atravesar el espesor de largos entramados textuales" (Fundéu, 2012: 66). Otro aspecto que los manuales destacan es el uso de un lenguaje literal: "el lenguaje metafórico puede ser una forma de confundir: algunas metáforas tienen sentidos diferentes según la geografía y otras tal vez no sean bien entendidas por los buscadores" (Fundéu, 2012: 328).

Los atributos del medio (ingreso permanente de información) se proyectan sobre el lector (se señala que este no tiene límites) ya que se lo inscribe en la isotopía de la potencia juvenil y se le asigna un valor subjetivo:

El lector digital no tiene límites: su periódico se actualiza en forma permanente y no cesa de entregarle nueva información.

La rapidez y la brevedad informativa se asocian al dinamismo del lector:

El lector digital no tiene mucho tiempo: el contenido debe ser rápido, directo, fluido, totalizador.

El lector digital necesita rapidez, contundencia y economía de lenguaje.

El lector digital necesita selección adecuada de contenidos, no abundancia.

Se destaca el centramiento sobre sus propios intereses:

9. Los resaltes, que estaban en negritas en el original siguiendo la tendencia de muchos textos en línea, son remplazados por itálicas para facilitar la lectura.

10. Los anteriores segmentos entrecomillados corresponden a estas páginas. 
Busca solo las noticias que le interesan. Quiere tener la oportunidad de elegir entre una amplia oferta, aquella información que le afecte según sus condiciones y aspiraciones personales.

Es un lector que se integra a comunidades virtuales que comparten sus intereses y se piensa como un par del periodista ya que las relaciones que entabla son entre iguales, es en cierta medida insensible a las relaciones asimétricas que puedan asignar un mayor conocimiento o una mayor información al otro:

Se siente más cercano al equipo de redacción de los periódicos digitales. La interactividad y la inmediatez que ofrece Internet le da la posibilidad de sentirse parte de la redacción y de charlar con los editores, cuestionar su trabajo y ser parte del periódico al proporcionar información.

Esto se debe al dominio de los saberes multimediáticos, que se presentan como centrales:

El lector digital ya piensa en multimedia: texto, audio, video, animación.

Eufóricamente se exaltan así determinadas condiciones, que en los ejemplos que señalamos, si bien no se oponen a la representación del lector del impreso, esta se puede inferir fácilmente. Cuando se la explicita en el texto referido se señala, entre otros rasgos, que el lector del impreso "sabe que está leyendo noticias de ayer", "debe someterse a los contenidos que le impone el medio", "tiene tiempo para leer", "vuelve a leer lo que le ha interesado", "utiliza el periódico como un documento cuando lo considera necesario", "quiere mucho material para leer", "privilegia el texto escrito y la fotografía”, "tiene un límite: la edición se cerró a determinada hora”. Este lector, al que se dirige la versión en soporte papel, capaz de reflexionar y volver sobre el texto, no es el lector considerado entusiastamente por los manuales que contemplan la versión on line. El medio recorta, así, dos tipos de lectores a los que les asigna características estables no como posibilidades alternantes en un mismo sujeto de dos maneras de leer la información o de incursionar en soportes diferentes.

El despliegue de la consigna "escribir para todos", cercana a la de la Gramática Básica "la gramática de todo el mundo", señala además un lector no localizado por lo cual se requiere un "español global" - "neutro y sin localismos" (Fundéu, 2012: 51), definido como "un idioma que es comprensible para todos, prescindiendo de sus rasgos locales” (Fundéu, 2012: 51) - lo que supone también un lector insensible al entorno cuando debe reconocer significados y no expuesto a las múltiples situaciones de contacto muchas de ellas desarrolladas por los medios audiovisuales. Associated Press (2012) señala que "el estilo periodístico ideal" es "el que antepone los términos de comprensión universal a los localismos". En cuanto a los préstamos que ingresan masivamente por Internet, las autoridades normativas, por un lado, "recomiendan utilizarlos en su justa medida, priorizando las palabras equivalentes en español” (Fundéu, 2012: 101) y, por otro lado, velan por su unificación en el área del español difundiendo las respuestas a demandas a través de la Fundéu en Internet o en el soporte papel con largas listas que figuran en el Manual del español urgente o en los otros. 
Asimismo, se piensa en un lector desprendido de rasgos particulares: "Escribir para todos también es crear contenidos accesibles independientemente de las capacidades físicas, intelectuales o técnicas de la audiencia" (Fundéu, 2012: 50). En otro tramo el mismo manual insiste:

Con qué problemas nos podemos encontrar:

- retrasos mentales

- problemas de carácter sociocultural

- baja capacidad de comprensión del idioma.

Cómo debemos plantear la redacción de los contenidos:

- utilizar un lenguaje directo y sencillo

- evitar expresar más de una idea por frase

- no usar tecnicismos ni abreviaturas

- realizar estructuras claras y coherentes en la organización. (Fundéu, 2012: 425)

Associated Press (2012) se centra en el registro y aconseja un "tono conversacional", lo que expande señalando:

Como si el autor le estuviera contando al lector lo que ocurre de manera correcta pero sencilla, como para que sea entendida por una persona de inteligencia promedio. Conviene que cada periodista se forme una idea de quién es ese lector imaginario: una posibilidad sería imaginarlo como un estudiante promedio de los últimos años de la escuela secundaria, equivalente al "high school" en Estados Unidos. (Associated Press, 2012)

La representación que los manuales de estilo periodístico proponen del lector orienta las decisiones respecto del armado de las oraciones y del despliegue discursivo. Las normativas retoman muchas de las indicaciones contenidas en variados textos acerca de la escritura en Internet, de allí la reiteración de las mismas observaciones en diferentes manuales. Como los textos fuente parten del inglés no dejan de proyectarse aspectos de la prosa informativa en esa lengua sobre las otras, en nuestro caso las románicas. 


\section{El título y los copetes: zonas en las que se despliegan las normas sobre la oración}

La importancia del título deriva en primer lugar de que se constata que "cada vez más lectores sacian sus necesidades informativas a base de leer exclusivamente titulares en las portadas de los diarios online"11 (Fundéu, 2012: 339). Por ello, "si se ha escrito un texto sublime pero no se encuentra el titular adecuado es como si no se hubiera escrito nada” (Fundéu, 2012: 341). Pero atraer al lector (y, en algunos casos, estimular su aporte) y facilitar la búsqueda de la noticia van a determinar el tipo de títulos: "deben ser cortos, más directos, concisos, claros y atractivos" y deben evitar totalmente "la utilización de metáforas que pueden llevar a la confusión sobre su significado" (Fundéu, 2012: 340). Cuando se ubica en el "Ahora”, sección que indica la inmediatez con la noticia, La Voz (2006: 173) señala: "el título debe combinar referencialidad y seducción para que no pierda valor informativo y tampoco atracción para el lector". Estas exigencias van a imponer una serie de normas para la escritura de los títulos y del copete, que se ilustran con reformulaciones correctivas de enunciados cuestionados. Aquí también se retoma una práctica común de las artes de escribir, que desarrollaban una pedagogía del error.

En primer lugar, la información nueva o más importante debe iniciar el título: en lugar de "Las diez claves de la gramática multimedia" escribir "La gramática multimedia, diez claves" (Fundéu, 2012: 327). Associated Press (2012) también va a aconsejar "ordenar los elementos empezando por lo más importante". El ejemplo se refiere a una información referida en estilo indirecto. "En vez de decir 'La Organización Mundial de la Salud informó que el número de pacientes de tuberculosis ha bajado por primera vez' reordenar diciendo: 'El número de pacientes de tuberculosis ha bajado por primera vez, informó la Organización Mundial de la Salud’”. Se anula así el juego de focalizaciones diversas, que pueden derivar de lo que se quiere tematizar en función del entorno discursivo o de un contexto situacional que puede ser polémico. Se tiende, entonces, a establecer un único orden discursivo que homogeneiza los intereses y que excluye toda posible capacidad de contextualizar.

La misma agencia señala que se debe personalizar, entendiendo por esto "hacer hincapié en los seres humanos y alumbrar aspectos de la condición humana":

Es una manera de pasar de lo abstracto a lo concreto. Por ejemplo, la noticia "Una investigación ha demostrado que los accidentes son proporcionalmente más frecuentes en las motocicletas, y son de naturaleza más violenta" queda mucho mejor si la damos vuelta para que diga "Los motociclistas tienen una proporción mayor de accidentes que los demás conductores y a menudo reciben heridas más graves, según una investigación". (Associated Press, 2012)

11. Por ahora, es en las portadas donde se aprecian en la mayoría de los periódicos cambios significativos, no en las notas. 
Por otra parte, en el caso del título 1 (destinado a lectores del Ahora), La Voz (2006: 174) señala entre otras observaciones:

El título debe "construir novedad" [respecto de la edición impresa].

Por ejemplo:

Edición impresa: Los recolectores de basura realizarán un paro ${ }^{12}$

Ahora: Los recolectores defienden el paro (si no hay ningún dato nuevo). (La Voz, 2006: 174)

Como vemos, la restricción de la condición de diferido del discurso escrito impone la consideración del tiempo verbal y de la acción evocada. En otros casos la "informatividad" exige desplegar las acciones generales enunciadas:

El título debe ser siempre informativo. Las descripciones de las acciones a veces no bastan.

Por ejemplo, hay que evitar títulos como este:

Habló el gobernador.

Y utilizar en cambio formas como:

El gobernador rompió el silencio y rechazó aumentos. (La Voz, 2006: 174)

A la metáfora lexicalizada se la descongela y literaliza para que gane en explicitación ("rompió el silencio") y se presenta el objeto del decir ("rechazó aumentos").

Associated Press (2012) se va a inclinar, como dijimos, por el uso de "verbos fuertes":

El verbo es el alma de la noticia. Además de ser el núcleo de la información es el elemento dinámico y no conviene neutralizarlo ni debilitarlo. Por lo general los verbos más comunes y más usados son los más débiles. En vez de verbos generales, imprecisos, rutinarios, conviene sustituirlos por otros más concretos, precisos y originales. Algunos de los verbos utilizados perezosamente: hay, tiene, está, dice. Ejemplos de verbos fuertes: "El papa Juan Pablo II ECLIPSÓ a Fidel Castro", "Xavier Cugat, el músico catalán de minúsculo bigote cuyos ojos SE ACHINABAN mientras sonreía". (Associated Press, 2012)

No se discute la relación entre la supuesta fuerza del verbo y la perspectiva subjetiva y manipuladora del enunciado. Superar la debilidad es dejar expandir la subjetividad en la información periodística, pero esto se deja de lado ya que lo importante es estimular y atraer al lector. Además, la normativa estilística no se interroga sobre si puede entrar en contradicción con principios que sostiene en otro lugar como "el periodismo es idealmente desinteresado. Esto permite distinguir el mensaje periodístico del mensaje publicitario, que tiene por objeto la promoción de un producto, un servicio o la ima-

12. Las negritas del original fueron remplazadas por itálicas. 
gen de una organización". Es evidente que el eclipsó del ejemplo propuesto aprecia diferentemente la figura del Papa y la de Fidel Castro.

En cuanto al estilo de los copetes, se privilegia el "telegráfico", que implica opciones respecto de los signos de puntuación:

Hay que evitar los punto y coma (;) y las subordinadas. El estilo telegráfico es el más adecuado cuando la información es compleja y debe ser presentada de modo sintético. Los copetes deben facilitar una lectura rápida utilizando frases simples y directas.

Incorrecto:

El próximo viernes, a las 11, el intendente tomará juramento a los nuevos miembros de su gabinete.

Correcto:

El intendente tomará juramento a los nuevos miembros de su gabinete el próximo viernes a las 11. (La Voz, 2006: 176)

Lo directo tiene que ver con el tradicional orden directo de los constituyentes de la frase: sujeto, verbo, objetos y circunstancias.

También se recomienda evitar los verbos en infinitivo y utilizar siempre que sea posible las conjugaciones [o las nominalizaciones].

Incorrecto:

El ministro de salud dijo no poder creer que la Municipalidad haya rechazado hacer estadísticas de infectología.

Correcto:

El ministro de Salud se mostró sorprendido por el rechazo de la Municipalidad a realizar estadísticas de infectología. (La Voz, 2006: 176)

La reformulación no solo presenta el resultado del decir y nominaliza el decir del otro sino que también disminuye la dimensión dialógica suprimiendo la doble negación que se piensa que dificulta la lectura de alguien no entrenado. Se considera mejor presentar las palabras de los personajes ya interpretadas. 
Al no entrenamiento en otros juegos remite la siguiente observación:

El lector español no tiene sentido del humor, no entiende los dobles sentidos, cree que los titulares con guiño esconden informaciones frívolas. Para los lectores la prensa debe ser seria. La parte cómica hay que dejársela a las publicaciones humorísticas. (Fundéu, 2012: 341)

En suma, las normas sobre titulares y copetes vuelven sobre la representación de un lector minorizado, que no puede completar la información textual con conocimiento previo, discursivo o enciclopédico, o con remisión a otras zonas del texto o activando saberes contextuales. Es un lector que tiene dificultades con el orden "inverso", que no puede contrastar afirmaciones de distintos enunciadores en una misma frase, que comprende lo literal pero no lo metafórico, y que finalmente no entiende los dobles sentidos porque carece del sentido del humor. Es posible que la presencia dominante de textos elaborados desde esa normativa incida posteriormente en un escaso desarrollo de estas actividades intelectuales, lo que debería ser evaluado en las indagaciones sobre el "cerebro digital" (Fiorentino, 2013).

\section{La estructura de los artículos}

Los textos deben estructurarse teniendo en cuenta "cómo leen los usuarios, qué están buscando y adaptarse a ello. [...] Ahora el usuario es el rey" (Fundéu, 2012: 63). La expresión convoca otra, "el niño es el rey", y al hacerlo muestra la subalternización del lector a la que los medios tienden a pesar de los eufóricos elogios que le asignan. Se plantea un corte radical con el pasado, al que se ridiculiza con enumeraciones heterogéneas: "se deben dejar a un lado los conocimientos acerca de la estructura de la redacción que se tengan del pasado: introducción, nudo, desenlace; frases pasivas, palabras líricas y rimbombantes" (Fundéu, 2012: 64). Incluso se plantea este modo de lectura propuesto como el único en la actualidad: "hace no tantas generaciones los textos se leían completos, siguiendo un orden establecido y conociendo el todo. Hoy en día escaneamos la información de un vistazo, seleccionamos lo que nos interesa y directamente saltamos de una información a otra" (Fundéu, 2012: 81-82). Este escaneo ha llevado a proponer la figura de la F como patrón de lectura: "nuestros ojos dirigen su mirada hacia la parte superior izquierda de la pantalla para luego continuar la exploración de arriba abajo y por su lado izquierdo" (Fundéu, 2012: 332). Sin embargo, se reconoce que en algunos casos puede haber "lectores metódicos" que "cuando hay un artículo que les interesa sobremanera dejan de ser usuarios scanner" y hacen una lectura "más detenida del contenido" (Fundéu, 2012: 85). Pero esto no altera el dispositivo normativo.

La figura dominante del lector orienta diversos aspectos de la escritura, entre otros, que las historias cortas se leen más que las largas (Fundéu, 2012: 330). En uno y otro caso hay que "elegir las palabras adecuadas; contar una historia en Internet puede resultar un poco engorroso, pero si se le dedica un poco de tiempo se acabará dando con las teclas idóneas" (Fundéu, 2012: 51). Pareciera pensarse en relatos en los cuales no deben aparecer el suspenso, el enigma, las estrategias engañosas del narra- 
dor. Esto responde al ideal de estilo periodístico que señala Associated Press (2012): "SIN ADORNOS. No tiene digresiones que distraigan ni colorido innecesario".

Asimismo, y más allá de las indicaciones que tienen que ver con los colores o la tipografía, se establece que "los párrafos han de ser más cortos" y cada uno "debe contener una idea o tema", "la información prioritaria tiene que aparecer al principio" y se advierte que "no estamos frente a una escritura lineal con principio y fin sino hipertextual" (Fundéu, 2012: 61). La brevedad, entonces, va a establecer la norma: no escribir más del 50\% de lo que se hubiera escrito en la versión en papel (Fundéu, 2012: 45) y el hipertexto va a exponer la posibilidad, en los lugares que el texto admita, de expansión de una información que remite a espacios y modalidades variadas: "los hipertextos son palabras que [...] no solo poseen un significado sino que desencadenan acciones, por lo que son mucho más 'poderosas' que el resto" (Fundéu, 2012: 38). A pesar de este reconocimiento generalizado, las decisiones no son fáciles: dónde ubicar los enlaces, cuántos se deben utilizar para no dispersar demasiado la atención del lector, cómo evitar que los enlaces externos entusiasmen al lector con otro medio y abandone el de origen (Maeyer, 2012).

A esto se agrega, como vimos, en títulos y copetes: "frases cortas y de estructura simple, SUJETO + VERBO + PREDICADO", "evitar las subordinadas, el lenguaje barroco, la falta de puntuación”. Además, se debe insistir en "verbos en activa" que sostienen el ideal de una estructura "llena de acción" (Fundéu, 2012: 80). El dispositivo normativo señala:

[... n no tratar de incluir más de una idea por oración, dividir las frases, eliminar algunos incisos y convertir otros en cláusulas independientes, eliminar palabras innecesarias y repeticiones de información, reformular y simplificar para que la oración tenga de unas 20 a 30 palabras. (Fundéu, 2012: 324-325)

Recordemos que las artes de escribir ilustradas insistían no solo en el orden directo sino también en la unidad de la frase y proponían “purgar de paréntesis” la oración (Arnoux, 2008: 340). Es notable la permanencia de la asociación del orden directo con el natural, ya discutido y cuestionado en la reflexión occidental. En ese sentido, en los principios para una buena entrada, El Mundo (2002) afirma:

Sujeto, verbo y predicado. Las frases bien ordenadas son inmediatamente inteligibles. Una buena entrada tiene que ser inteligible. No se puede convertir esta regla en absoluta, ya que a veces es necesaria una estructura menos sencilla: entradas cuándo o dónde, por ejemplo, con sus participios en primer plano. Pero las oraciones más naturales siempre serán preferibles. (El Mundo, 2002: 30)

Se exalta, entonces, la concisión, el orden directo, la frase simple y el punto como signo de puntuación frente al punto y coma (“que se empleará solo para la enumeración”, La Voz, 2006: 166). La economía es la regla, así Associated Press (2012) plantea: "decir todo lo que debe decir con el mínimo de palabras". Y lo fundamenta: "Una estadística del Instituto de la Prensa Americana que publicó 
el Manual de Estilo de la Sociedad Interamericana de Prensa (SIP) halló que mientras más largo un párrafo menor la comprensión del lector: un párrafo de 20 palabras lo comprendía el 90\%, de 23 el $70 \%$, de 27 el 60\% y de 33 el 31\%".

El Mundo (2002), aunque reconozca que estos principios generales se pueden ver alterados en las crónicas largas, reportajes o artículos de opinión, reitera el ideal de prosa informativa:

Es norma general emplear oraciones simples, separadas por punto y seguido o punto y aparte. Las oraciones subordinadas son la excepción. Se debe también limitar al mínimo posible el recurso a las acotaciones entre rayas o entre paréntesis. Cada dos oraciones o, como mucho, tres se colocará un punto y aparte. Los párrafos de más de diez líneas justificadas [cinco de máquina de escribir o de pantalla de ordenador] son la excepción, no la regla. (El Mundo, 2002: 2)

Esto se debe a que el género que domina es la noticia o información básica. De los diversos géneros a los cuales un manual de estilo periodístico se puede referir (crónica, reportaje, noticia o información básica, entrevista, artículos firmados, editoriales, obituario, cartas al director, crítica...), en la versión en Internet se señala el peso de aquel género. El Mundo (2002), también, plantea:

La noticia ocupa hoy un lugar preponderante en la versión en Internet.

Este fue el género más habitual en la prensa diaria, al que se aplican más estrictamente las consideraciones sobre frases y párrafos cortos, entrada directa y desarrollo que puede ser cronológico o piramidal, según la complejidad menor o mayor de los elementos informativos. [...] No hay lugar para incluir opiniones o juicios de valor. (El Mundo, 2002: 6)

La Voz (2006: 166), por su parte, al dar la posibilidad de tres tipos de noticias insiste en las dimensiones ${ }^{13}$ :

Breves. La extensión promedio debe ser de dos a tres párrafos. En el primero se emplaza el foco de la noticia y la atribución de la fuente, aunque esto último puede hacerse también en el segundo. En el último párrafo debe contextualizarse brevemente la información [...].

Estándar. Cuando los acontecimientos están en desarrollo inicial o cuando la valoración que se hace de ellos es baja, la extensión de las notas debe rondar las 200-250 palabras. Esto implica la utilización de alrededor de cuatro párrafos: El empleo del hipertexto para la información de contexto y adicional es fundamental.

En profundidad. No deben superar las 400-450 palabras y hay que utilizar entre seis y ocho párrafos. El criterio fundamental para estas noticias es el de importancia. (La Voz, 2006: 166)

13. Las agencias de noticias también regulan la dimensión de sus cables. AFP estable la extensión según las rúbricas: "urgente" agrega al título entre 40 y 60 palabras, "alerta" contiene 80 caracteres como máximo (Charon y Le Floch, 2011: 87). 
Algunas indicaciones tienen que ver con aspectos puntuales como las expresiones temporales y los tiempos verbales, que se aplican también a títulos y copetes. En relación con las primeras se aconseja evitar frases que puedan quedar rápidamente desactualizadas para lo cual es necesario dejar de lado "expresiones como 'actualmente,' 'en los últimos tiempos', 'el año pasado,' 'ahora', etc.". La guerra a los deícticos se justifica, por otra parte, en el hecho de que pueden ser en otros momentos objetos de enlaces hipertextuales. Además, se propone actualizar los tiempos verbales para "no correr el riesgo de presentar como en curso sucesos que pueden haber concluido ya” (Fundéu, 2012: 328-329). También se sugiere evitar los entrecomillados "para aligerar el peso de toda la masa de texto" (Fundéu, 2012: 233). Otras son observaciones más generales para romper la uniformidad del texto corrido: se recomienda el uso de negritas y enlaces, además de "dividir un tema en subtemas y darle a cada uno un título propio", se puede pensar así en "pequeños titulares informativos para separar párrafos" (Fundéu, 2012: 330-331).

Entre las propuestas para estructurar el contenido se plantea, asimismo, el uso de listas de puntos: "Permiten ser conciso y persuasivo y hacen la lectura más cómoda y comprensiva". A ello se agrega "emplear sumarios de información para resumir el contenido del texto" (Fundéu, 2012: 323). Por otra parte, se aconseja "dividir la información en pedazos coherentes, centrados cada uno en un aspecto determinado, y enlazarlos” (2012: 325).

El despliegue textual tiene una importancia relativa ya que "no se lee todo porque se sabe que leyendo una parte uno ya puede imaginarse el texto completo, con una frase del párrafo se puede deducir de qué trata" (Fundéu, 2012: 66- 67). Se excluyen así operaciones de lectura detenida o de vuelta interpretativa sobre el texto. No se vislumbra la posibilidad de ningún gesto "meta" o crítico. Si bien la simplicidad del texto es también una simplicidad ideológica acerca de los medios, en algunos momentos se percibe el carácter manipulatorio de este modo promocionado de lectura: "Hay que pensar que el lector tiene que quedarse con la impresión que se le quiera dar” (Fundéu, 2012: 66).

La imagen de la pirámide invertida es, como dijimos, recurrente:

[...] invertir la argumentación clásica de introducción, nudo y desenlace. Es preferible poner siempre al principio del texto lo más importante, para dejar al final lo menos relevante: primero las conclusiones o el gancho, después las ventajas o la historia más interesante y al final la orientación para los que quieran ampliar. (Fundéu, 2012: 67)

Al considerar la noticia en el proceso de elaboración periodística se propone otra figura, la del diamante, que combina velocidad con profundidad y que tiene en cuenta la diversidad de textos y el proceso constructivo que se va generando en torno a una noticia. En este caso no se focaliza el texto sino el paso de uno a otro y los lugares en los que se introduce la interactividad, la hipertextualidad y la multimedialidad: 
Se comienza con la alerta, que da paso al primer borrador de la noticia, que ya puede ser publicado en un blog como adelanto; le sigue el artículo, que incorpora comentarios de lectores y que puede ser incluido en medios impresos. Luego se aporta el contexto con la incorporación de multimedios y enlaces hacia otros recursos. Más tarde aparece el análisis y con él llega la interacción con diferentes tipos de recursos que facilitan la participación. El paso final es la personalización, que debería ser automática y permitir que los usuarios obtengan la información por diferentes vías y de acuerdo a sus necesidades. (Fundéu, 2012: 337)

Algunos criterios como los de simplicidad, brevedad, estilo directo y esquematizaciones y resaltes, que los manuales de estilo buscan imponer para el género privilegiado, la noticia, parten del ilusorio ideal de un lenguaje transparente, donde domine lo literal y se eviten las complejidades sintácticas que resultan del uso afinado de una herramienta semiótica que modela el pensamiento y modaliza las afirmaciones. Los que consideran las cadenas discursivas integran los aportes de Internet al periodismo digital y contemplan el vínculo con la edición papel.

\section{Desplazamiento de la transparencia lingüística a la limpieza mo- ral: la netiqueta}

Como los medios periodísticos incluyen secciones en las que los lectores se manifiestan, resulta necesario establecer normas de netiqueta (etiqueta en la red), para cuya aceptación por parte de los colaboradores espontáneos se advierte que el incumplimiento afecta no solo la identidad virtual sino también la real ya que esta o se expone o no resulta difícil de reconocer. Si bien muchos periódicos no han avanzado en la elaboración de manuales de estilo para la prensa digital, establecen guías de moderación o reglamentos de participación (Sal Paz, 2014: 180). Estos van de observaciones sobre el lenguaje adecuado a prohibir los enunciados contrarios a las leyes, la moral y las buenas costumbres, o los mensajes agraviantes. Por su parte, las normas destinadas a los periodistas se dedican a aspectos lingüísticos y discursivos variados. Así, van de atender a las fórmulas de tratamiento que se utilizan y cuidar la forma de expresarse a hacer "contribuciones relevantes y ciertas", ofrecer "un texto bien estructurado", "tener en cuenta las diferencias culturales" (Fundéu, 2012: 5354) o evitar las palabras malsonantes. Parte de la netiqueta es también evitar los malentendidos, ya que como señalamos se piensa en un lector incapaz de reconocer las opacidades del texto ni los juegos de sentido propios de la densidad semántica de algunas construcciones. Se insiste así en la literalidad discursiva.

Los "decálogos" se desplazan fácilmente del lenguaje a los comportamientos y establecen normas que o son obvias o son difícilmente regulables:

- No olvidar nunca que quien lee el mensaje es una persona y tiene sentimientos que podemos ofender. [...]

- Mostrar lo mejor de nosotros mismos mientras estemos en Internet. 
- Compartir nuestro conocimiento con la comunidad.

- Ayudar a mantener los debates en un ambiente sano e instructivo.

- Respetar la privacidad de terceras personas.

- No abusar del poder.

- Perdonar los errores ajenos. (Fundéu, 2012: 54-55)

En un blog-journal creado en España, Periodismo independiente, que se define "con una clara vocación universalista y europeísta" y como "defensores de la democracia liberal y de la libertad de pensamiento", en su escueta parte "Sobre el tratamiento del lenguaje" se señala:

El propósito de publicar hechos, opiniones, ideas y propuestas a un público heterogéneo obligan al escritor a utilizar un estilo de redacción claro, conciso, fácilmente comprensible y fluido. Todo ello, con el único fin de captar la atención y el interés del lector. Por ello, las expresiones malsonantes, vulgares, obscenas o blasfemas están prohibidas y deberán evitarse en el grueso del artículo salvo que se trate de citas textuales. Y aún así, deberán proceder de personas relevantes en la historia. De la misma forma nunca deberán utilizarse frases que resulten ofensivas para cierta comunidad de individuos y deberá procurarse siempre evitar los eufemismos y las palabras bien sonantes que pretenden esconder la realidad de los hechos descritos. (Periodismo independiente, 2013: 3)

La consecuencia que se marca con el "por ello" establece una equivalencia entre el estilo "claro, conciso, fácilmente comprensible y fluido" y otra limpieza, la que evite "expresiones malsonantes, vulgares, obscenas o blasfemas". También esto último puede ser leído como una restricción al objetivo de "captar la atención y el interés del lector". Lo que se vislumbra es una ética de la comunicación escrita asociada con la figura de un lector, como señalamos, no dotado de estrategias defensivas frente al texto, que es afectado o influido fácilmente, un lector no entrenado en modalizaciones ni registros, en el que la lectura literal es central y su vocabulario, o las posibilidades de comprensión de términos a partir del entorno, limitado. Por otra parte, el cierre muestra una tensión no resuelta entre el estilo directo y claro y lo políticamente correcto. A esto último también se refiere el siguiente fragmento:

Si los mensajes giran en torno a temas sensibles para la sociedad, como inmigración, guerras, homosexualidad, etc., hay que prestar particular atención a la corrección del lenguaje. Los términos políticamente correctos pueden ayudar siempre y cuando seamos conscientes de la zona y el contexto en que se utilizan. (Fundéu, 2012: 61)

El manual de la Fundéu al referirse al respeto y la cortesía considera que debe inscribir su propósito en una tradición respetable: 
Como en los manuales de cortesanía de la época clásica, se aconseja que los usos idiomáticos en los nuevos medios estén presididos por el respeto y la cortesía hacia el interlocutor.

(Fundéu, 2012: 16)

Como vemos, los manuales de estilo periodístico de última generación consideran entre sus funciones regular a través de los usos lingüísticos la vida social (virtual). Por eso se plantea que "las dudas" a las que se responde "no son estrictamente lingüísticas, sino también de urbanidad y de tipo técnico" (Fundéu, 2012: 22). La urbanidad, si bien es un aspecto menor, se inserta en la necesidad del género "manual de estilo" de destacar la dimensión ética de la escritura informativa y acompañar de esta manera los declarados y generales principios, que aparecen en todos los ejemplares: responsabilidad, veracidad, confiabilidad de las fuentes, verificación de la noticia. La ética se presenta como lo que sostiene un contrato que surge del respeto al lectory del propósito de facilitar su comprensión del texto. En esto se vincula también con las artes de escribir que insistían en ese sentido sobre la ética de la comunicación escrita aunque por razones de época no pensaran en la introducción en el texto de palabras malsonantes.

\section{Algunas reflexiones finales}

Abordar las ideologías lingüísticas en la prensa escrita nos impone interrogar los dispositivos normativos que conforman los manuales de estilo periodísticos y, en la actualidad, aquellos destinados a las versiones on line. En estos podemos relevar representaciones acerca del ideal de lengua y de discurso derivadas de la construcción que hacen del lectory de los modos de leer las informaciones que las empresas producen. De allí la exigencia para los escritos de homogeneidad lingüística, brevedad, claridad, orden directo de las palabras en la frase, valoración de lo concreto, limitación de las metáforas y los dobles sentidos, control de las subordinaciones, exclusión del punto y coma, los paréntesis y las rayas, inserción de las palabras de los otros ya interpretadas, contextualización permanente suministrada por el medio y estímulos a la interacción. Todo ello tiende a facilitar la lectura de un sujeto que se avizora con competencias discursivas e inferenciales limitadas, que navega al imperio de sus intereses y cuya atención fácilmente desfallece. Por otro lado, es un lector global que puede entender las formas neutras de un español internacional pero que, egoístamente, se resiste a las marcas locales de los otros. Todo lleva a una representación minorizada del posible destinatario, que se compensa con la exaltación de los atributos de juventud y dinamismo propios de los discursos publicitarios.

La regulación de la prosa informativa, centrada en un lector no entrenado en textos complejos, acerca estos manuales a las artes de escribir de fines del siglo XVIII y comienzos del XIX, mostrando la permanencia de ciertas representaciones en relación con desafíos próximos. Aquellas respondían también a una necesaria ampliación de la cultura escrita pero motivada, en esa etapa, por el desarrollo de la sociedad industrial, la aparición de nuevas formas de representación política y la conformación de las identidades nacionales a partir de las lecturas compartidas. En este comienzo del siglo 
XXI se plantea otra vez la necesidad de extender el número de lectores, en este caso pensados como consumidores de los productos globales. El apoyo es un soporte diferente, el digital, que permite alcanzar a un público planetario y a un mayor abanico de franjas etarias, lo que para los medios periodísticos es la garantía de su supervivencia. En función de ello se construye una representación de lector poco dotado de habilidades lingüísticas y discursivas y se establece un dispositivo normativo respecto de la escritura que le facilite su rápido recorrido por las informaciones a la vez que le dé los instrumentos para actuar y colaborar limpia y cortésmente con los medios periodísticos. Se piensa en una homogeneización de la lengua y de las prácticas con ella asociadas, que, paradójicamente, entra en contradicción con el declarado elogio de la diversidad que los mismos medios exaltan en otros campos.

Pensamos que el tipo de escritura que promueven (aunque todavía no afecta en general a gran parte de los textos de prensa), si bien parte de los rasgos que se atribuyen a la lectura en pantalla, no dejará de reforzar modos de leer y de escribir uniformes y simplificados que incidirán en los modos de pensar (si seguimos considerando a la escritura una herramienta semiótica fundamental del desarrollo intelectual). Esperemos que solo sea una reacción primera para ampliar la audiencia y no una ideología y práctica continuas que modelen en forma dominante la lengua y la discursividad de sectores de la población en los que, al constituir el consumo preponderante, se acentúe su carácter subalterno. Debemos pensar que las ideologías lingüísticas, en este caso respecto de la lectura y la escritura en la red, no son ajenas al establecimiento y reproducción de las diferencias sociales. Así, los miembros de las clases dirigentes y de los sectores vinculados a ellas, a la vez que incursionan en estos modos de leer y de escribir, consumen variados discursos con múltiples grados de complejidad, tipos de despliegue y juegos de sentido y son sensibles a las diferencias sociolingüísticas y a la diversidad propia de toda lengua histórica. En ellos las nuevas prácticas enriquecerán el abanico de posibilidades con las que cuentan, no así en las clases populares, sobre todo en una época en la que, para las grandes mayorías, la acción del sistema educativo no resulta compensatoria. En suma, los manuales de estilo periodístico destinados a las versiones on line promueven prácticas y representaciones que pueden incidir, por la potencia y expansión de las nuevas tecnologías, en la reproducción social de un mundo con diferencias cada vez más acentuadas. 


\section{Bibliografía}

Arnoux, Elvira Narvaja de (2000), "La Glotopolítica: transformaciones de un campo disciplinario", Lenguajes: teorías y prácticas, Buenos Aires, Gobierno de la Ciudad de Buenos Aires, Instituto Superior del Profesorado "Joaquín V. González", p. 95-110.

Arnoux, Elvira Narvaja de (2008), Los discursos sobre la nación y el lenguaje en la formación del Estado (Chile, 1842-1862): estudio glotopolítico, Buenos Aires, Santiago Arcos.

Arnoux, Elvira Narvaja de (2011), "Desde Iguazú: mirada glotopolítica sobre la integración regional”, en Adrián Pablo Fanjul y Greice da Silva Castela (eds.), Línguas Políticas e ensino na integração regional, Cascavel, Assoeste, Universidade Estadual de Oeste de Paraná, p. 38-64.

Arnoux, Elvira Narvaja de, María Imelda Blanco y Mariana di Stefano (1999), "Las representaciones de la lengua y de la prensa en los manuales de estilo periodísticos argentinos", en Elvira Arnoux y Roberto Bein (eds.), Prácticas y representaciones del lenguaje, Buenos Aires, Eudeba, p. 175-190.

Arnoux, Elvira Narvaja de y José del Valle (2010), "Las representaciones ideológicas del lenguaje: discurso glotopolítico y panhispanismo", Spanish in Context, vol. 7, n 1 (Ideologías lingüísticas, bajo la dirección de José del Valle y Elvira Narvaja de Arnoux), p. 1-24.

Associated Press (2012), Manual de estilo (en español), disponible en http://www.manualdeestiloap. com/. [Sitio consultado el 12 de octubre de 2013.]

Auroux, Sylvain (1994), La révolution technologique de la grammatisation, Lieja, Mardaga.

Charon, Jean-Marie y Patrick Le Floch (2011), La presse en ligne, París, La Découverte.

El Mundo (2002), Libro de estilo del diario El Mundo, disponible en www.masmenos.es/wp-content/ uploads/2002/01/librodeestilo_elmundo.pdf. [Sitio consultado el 10 de marzo de 2014.]

Fiorentino, Giuliana (2013), Frontiere della scrittura: lineamenti di web writing, Roma, Carocci editore.

Fogel, Jean-François y Bruno Patino (2007), Une presse sans Gutenberg: pourquoi Internet a bouleversé le journalisme, París, Seuil.

Fundéu (Fundación del Español Urgente) (2008), Manual del español urgente, Madrid, Cátedra.

Fundéu (Fundación del Español Urgente) (2012), Escribir en Internet: guía para los nuevos medios y las redes sociales (Mario Tascón, ed.), Barcelona, Galaxia Gutenberg.

Gómez Font, Alberto (1998), "Los libros de estilo de los medios de comunicación en español: necesidad de un acuerdo”, Espéculo, disponible en https://pendientedemigracion.ucm.es/info/ especulo/ele/g_font.html. [Sitio consultado el 10 de marzo de 2014.]

La Voz del Interior (2006), Normas de estilo de Lavoz.com.ar y de Córdoba.net, disponible en archivo. lavoz.com.ar/institucional/pdf/manual.pdf. [Sitio consultado el 10 de marzo de 2014.] 
Maeyer, Juliette de (2012), "Lien hypertexte et journalisme: où est la connexion?", en Rémy Le Champion (ed.), Journalisme 2.0, París, La Documentation Française, p. 81-88.

Nogueira, Sylvia (en prensa), "De la norma a la recomendación en manuales de estilo: el caso de Escribir en Internet de Fundéu BBVA”, en Elvira Arnoux y Daniela Lauría (eds.), Las lenguas en la construcción de la ciudadanía sudamericana, La Plata, Unipe Editorial Universitaria.

Periodismo independiente (2013), Manual de estilo, disponible en www.periodismoindependiente. es/manual-estilo/. [Sitio consultado el 10 de marzo de 2014.]

Sal Paz, Julio César (2014), "Comunidades, géneros y estrategias: conceptos operativos para caracterizar la interacción en los periódicos digitales", en Alejandro Parini y Mabel Giammatteo (eds.), Lenguaje, discurso e interacción en los espacios virtuales, disponible en http:// http://ffyl1. uncu.edu.ar/IMG/pdf/Parini_y_Giammatteo_eds_2014.pdf. [Sitio consultado el 15 de enero de 2014.] 